\title{
CULTURA DE JAMBOLÃO SOB DOSES DE LODO DE ESTAÇÃO DE TRATAMENTO DE ÁGUA
}

\author{
Amanda Jakelline Dias da Silva - amandajds14@ hotmail.com
}

Centro Universitário de Patos de Minas - UNIPAM

Isabela Ferreira Caixeta - isabelacaixeta31@hotmail.com

Centro Universitário de Patos de Minas - UNIPAM 


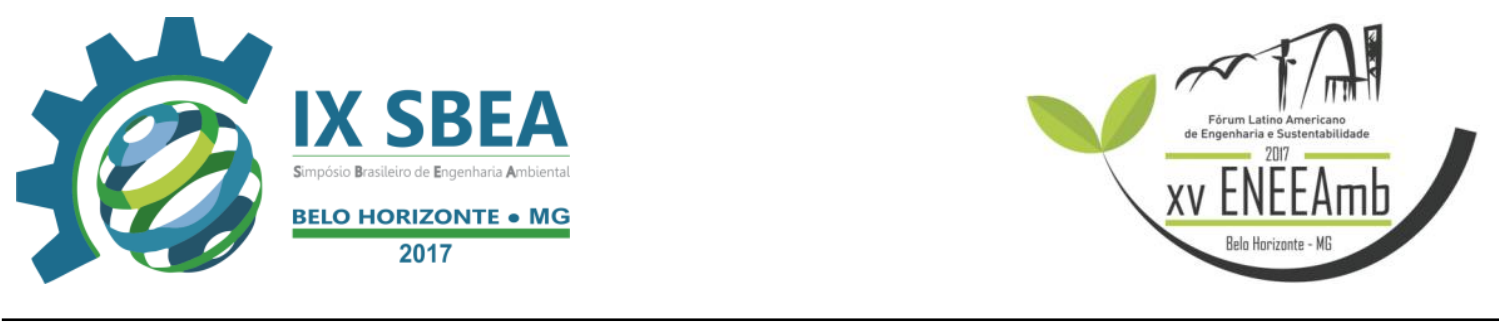

\section{RESUMO}

Atualmente tem se buscado uma destinação adequada para dejetos oriundos de estação de tratamento de água, esses dejetos normalmente possuem concentrações de nutrientes que poderiam ser utilizados como fertilizantes em plantas ou descartados em áreas de vegetação nativa. Sendo assim esse trabalho tem por objetivo avaliar a influência de biossólido de estação de tratamento de água no crescimento de plantas de Jambolão. O trabalho foi desenvolvido em casa de vegetação no Centro Universitário de Patos de Minas-UNIPAM, as plantas de Jambolão foram adquiridas no Instituto Estadual de Florestas-IEF, elas foram transplantadas para vasos plásticos com $11 \mathrm{dcm}^{3}$ de volume, e preenchidos com areia lavada associada à biossólido de tratamento de água, nas proporções referentes a cada tratamento. Foram realizadas avaliações como: tamanho da planta, quantidade de folhas, ramificações, folhas amareladas e teor de clorofila, em 44 dias. O delineamento experimental utilizado foi de blocos ao acaso constituídos por 5 tratamentos com 4 repetições. De acordo com os resultados obtidos a aplicação de biossólido de tratamento de água na dose de 8 gramas de Lodo de Estação de Tratamento de Água por quilo de areia, promoveu um maior crescimento na planta, porém ocasionou uma redução na massa seca de folhas em todas as doses, embora não tenha ajuste para equação de regressão para massa de folha.

Palavras-chave: Água, Tratamento, Biossólido, Jambolão.

\section{INTRODUÇÃO/OBJETIVO}

A grande expansão da população nas cidades fez com que aumentasse as exigências e investimentos no saneamento básico e também nos serviços de abastecimento de água. É nesse sentido que as estações de tratamento de água possuem um grande papel, pois são responsáveis pela adequação a qualidade da água que é abastecida para as populações dentre os padrões corretos de potabilidade, que são os padrões físicos, químicos e biológicos (ZANCAN et al. 2015).

Lodo das Estações de Tratamento de Água é o principal lançamento das companhias de saneamento nos corpos hídricos, o mais confiável é descartar o efluente 


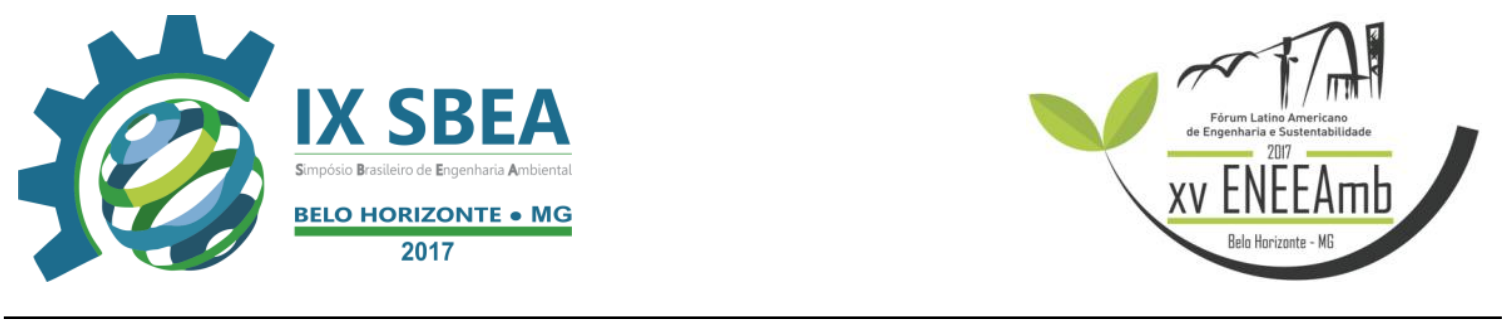

antes que ele perca toda a sua água, assim, quanto maior for à secagem desse resíduo mais fácil será o processo e manuseio do mesmo (PAIVA \& PARREIRA, 2012).

A NBR-10.004 (2004) foi que classificou as Estações de tratamento de água, ela não permite o lançamento in natura em águas superficiais (ABNT, 2004). O lançamento incorreto desse efluente pode vir a ser caracterizado como crime ambiental, por causa dos diversos efeitos que pode a vir causar no ambiente aquático do corpo receptor e danos à fauna aquática (ACHON et al., 2008).

A sua aplicação em terras agrícolas pode trazer alguns benefícios, como: melhoria na estrutura do solo, ajuste de PH, entre outros. No entanto, alguns estudos demonstram que o lodo de ETA, quando aplicado em terras agrícolas, tende a reagir e deixar vedado o fósforo presente no solo para a planta (GANDARA \& BERTON, 2010). Neste estudo, o lodo de estação de tratamento de agua será aplicado na espécie Syzygium cumini, o Jambolão (Syzygium jambolanum Lam.), aqui no Brasil, o Jambolão é mais consumido in natura, apesar da fruta ter diversas outras maneiras de consumo, como: tortas, geleias, entre outros (VIZZOTTO \& FETTER, 2009).

No Jambolão são identificados alguns elementos químicos chamados de fitoquímicos. Esses elementos são formados espontaneamente pelas plantas com a intensão de defesa de pragas e doenças, e também ajudam a defender das condições opostas do ambiente. Grande parte dos fitoquímicos trabalha na precaução e no combate de doenças crônicas como o câncer. Ainda a presença do polifenol, ácido elágico, tem que ser apontada por ser uma substância eficiente na prevenção de doenças crônicas não contagiosas (VIZZOTTO \& FETTER, 2009). Segundo estudos realizados por FERNANDEZ et al. (2000) o Jambolão é apropriado para solos com maior teor de Fósforo.

O objetivo desse trabalho é analisar o comportamento da espécie Jambolão (Syzygium jambolanum) em doses de lodo de estação de tratamento de água.

\section{METODOLOGIA}

O experimento foi realizado na estufa do Centro Universitário de Patos de Minas-UNIPAM no Bloco K. Neste experimento foi utilizado plantas de Jambolão. 


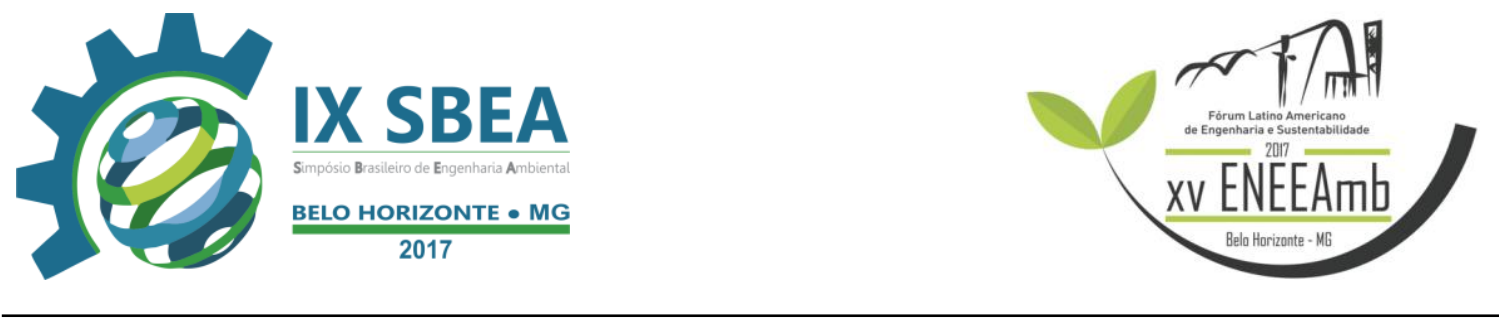

Foram preenchidos vasos de plásticos de $11 \mathrm{dcm}^{3}$ com $8 \mathrm{~kg}$ de areia. Depois de preenchidos, 20 plantas de Jambolão $+10 \%$ foram transferidas para os vasos.

Todos os dias as plantas foram irrigadas com 300mL de água e semanalmente nutridas semanalmente com a Solução Nutritiva de Johnson.

Foi colocado o Lodo de Estação de Tratamento de Água em cada planta em diferentes doses, e cada Tratamento e Repetição foi devidamente identificado.

Tabela 1: Tratamentos de Lodo de Estação de Tratamento de Água em quilos de areia

Doses

T1

T2

T3

T4

T5

Lodo de ETA (g por kg de areia)

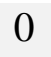

5

10

15

20

A partir do primeiro dia após colocar o contaminante foi medido o tamanho das plantas, contado as folhas, as ramificações e as folhas amarelas de quinzenalmente. Foi medido o teor de clorofila das plantas utilizando o clorofilômetro ClorofiLOG® ${ }^{\circledR}$ CFL 1030, fazendo uma média automaticamente, de 5 folhas aleatórias pelo aparelho.

No último dia de experimento, o caule, as raízes e as folhas foram separados e pesados para obtermos as massas das mesmas.

\section{RESULTADOS E DISCUSSÃO}

De acordo com a figura 1, constatasse o acréscimo na altura de planta.

Figura 1: Altura de plantas da espécie Syzygium jambolanum em 44 dias após ser aplicado o Lodo de Estação de Tratamento de Água 

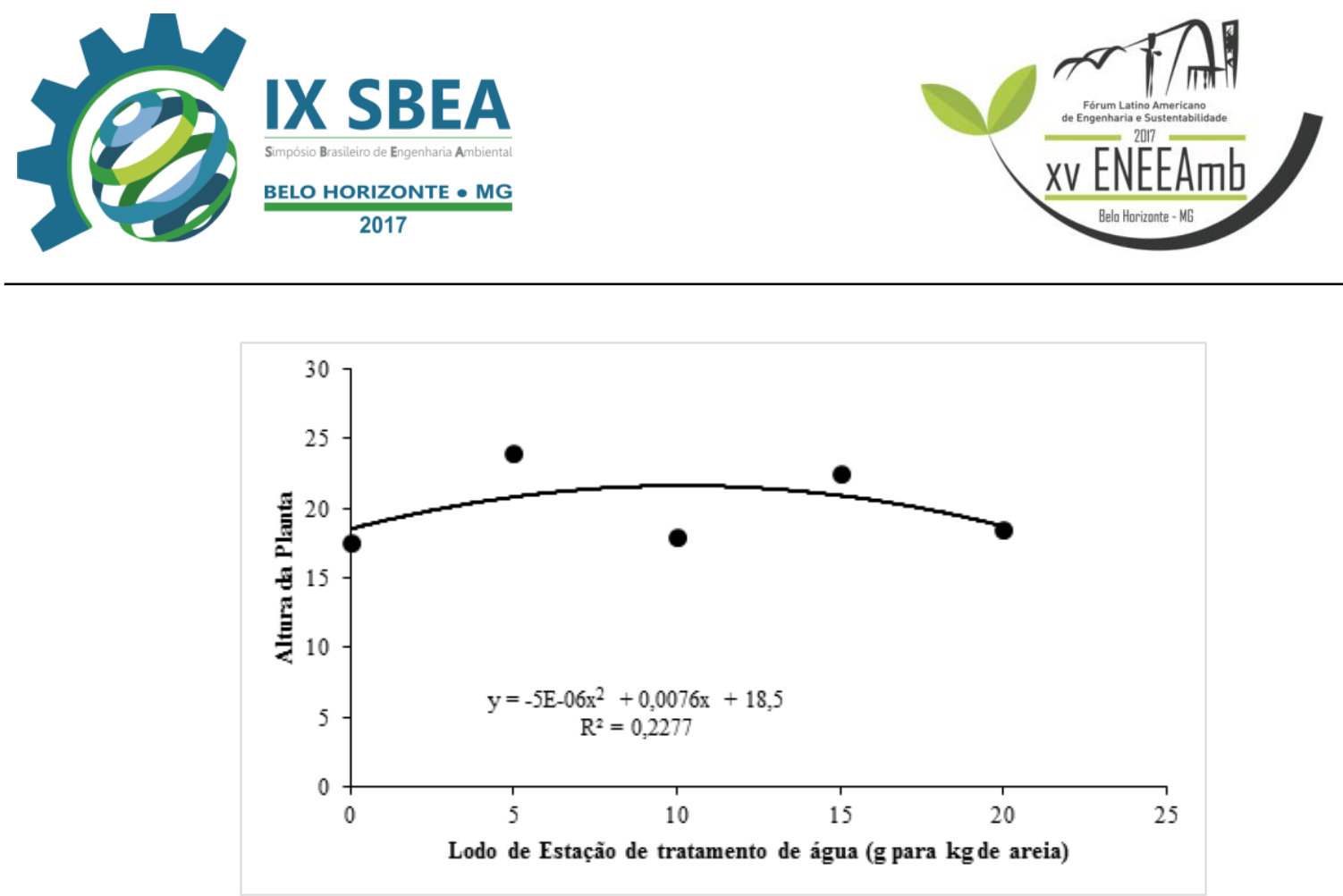

Seguindo a linha de tendência, houve um crescimento até a dose 10,5 e com o aumento dessa dose houve uma redução no crescimento.

Figura 2: Teor de clorofila das plantas da espécie Syzygium jambolanum em após aplicar o Lodo de Estação de Tratamento de Água

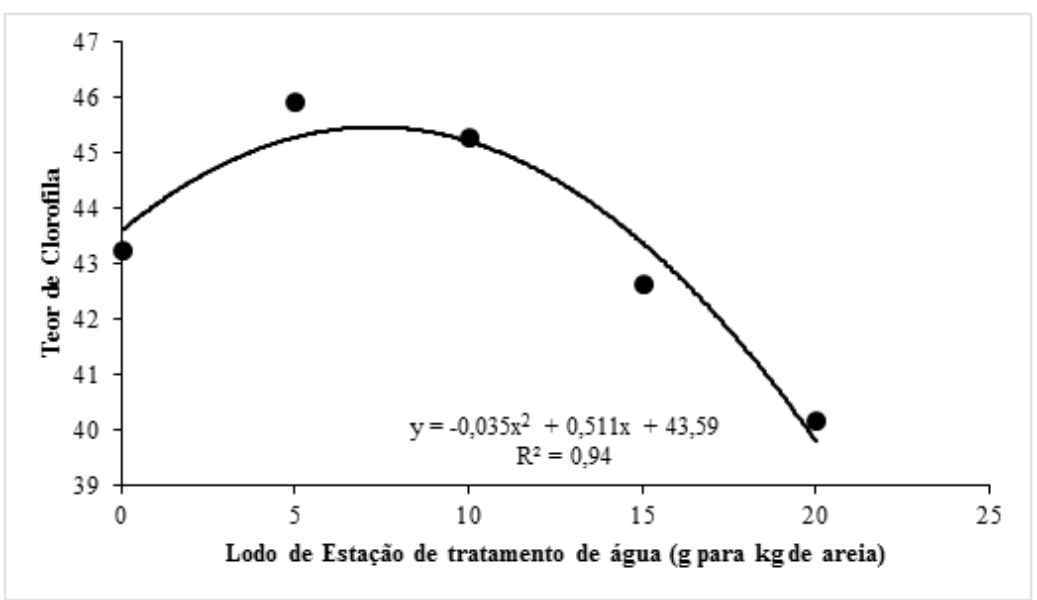

Ao analisarmos a figura 2, podemos perceber que 7,5 gramas de Lodo de ETA fez com que houvesse o aumento na produção de clorofila, após essa dose, houve um decréscimo.

Figura 3: Aumento de quantidade de folhas da espécie Syzygium jambolanum em 44 dias após ser aplicado o Lodo de Estação de Tratamento de Água 

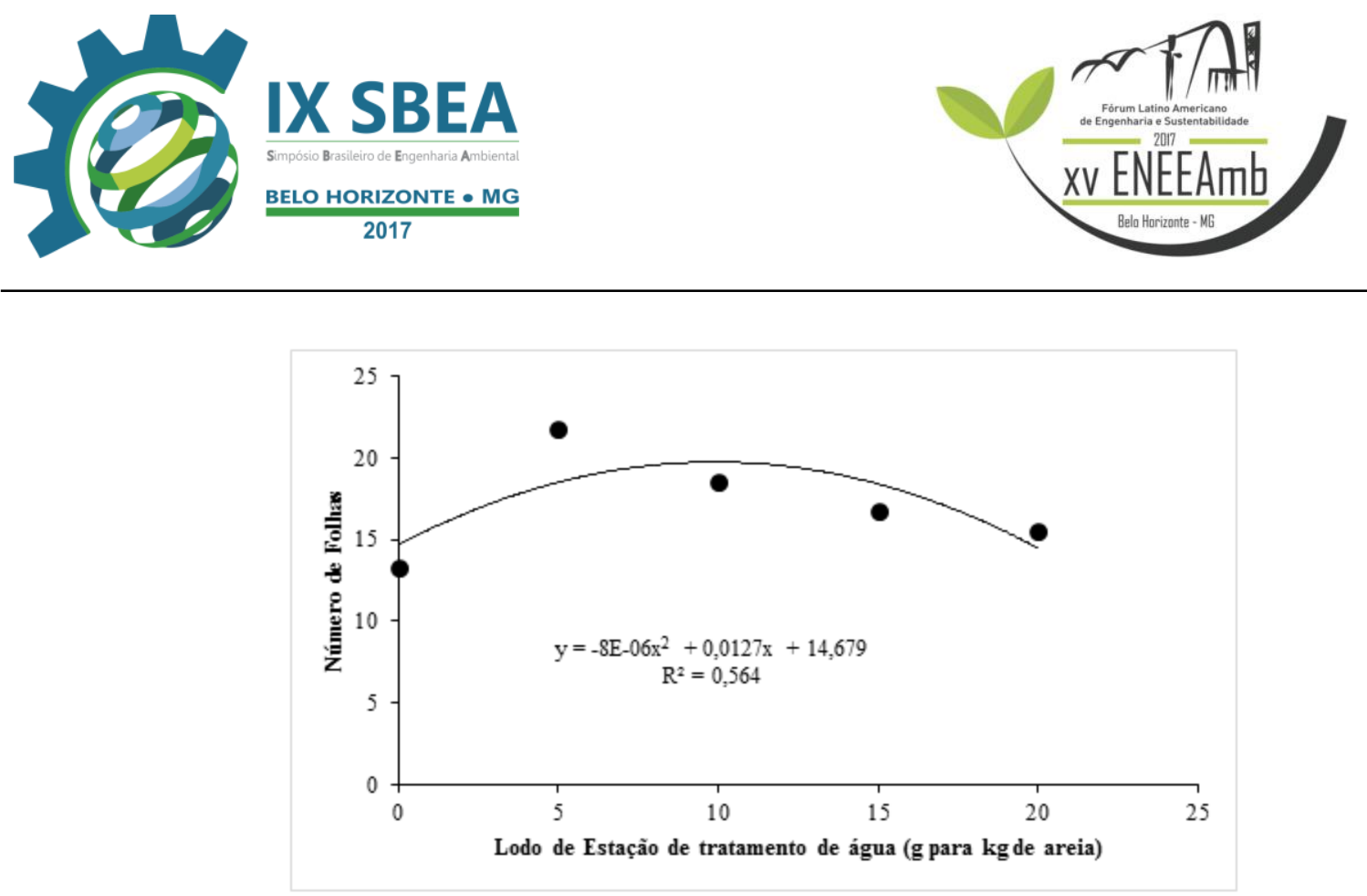

A figura 3 mostra que a dose T3 apresenta o aumento no número de folhas e ao ser aumentado, há um decréscimo.

Figura 4: Quantidade de ramificações nas plantas da espécie Syzygium jambolanum em 44 dias após ser aplicado o Lodo de Estação de Tratamento de Água

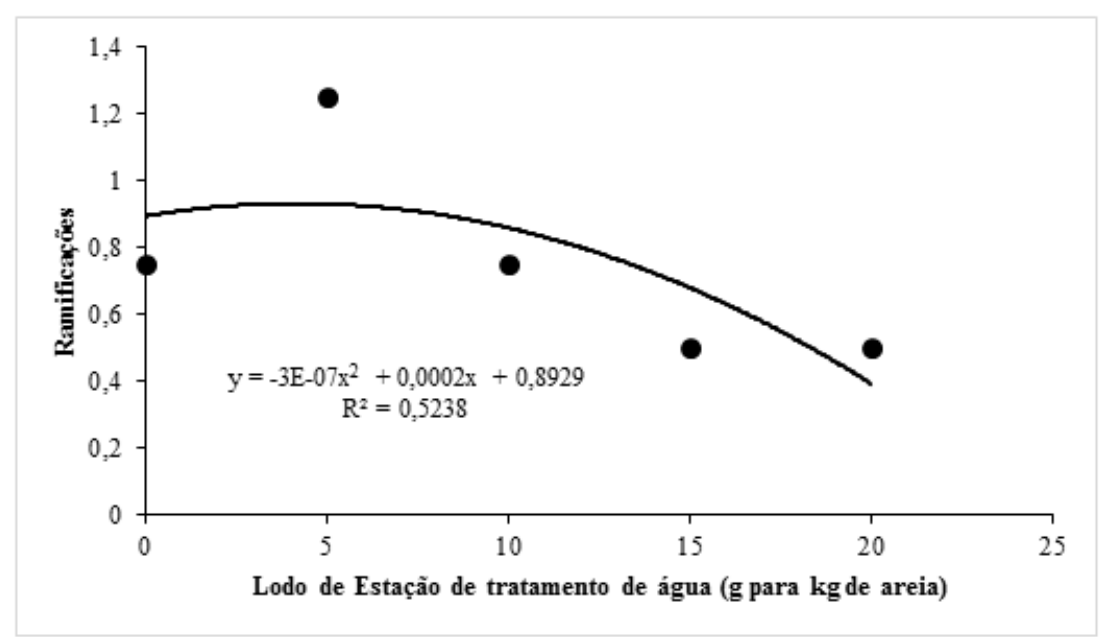

A figura 4 afirma que o tratamento 2 gera a maior quantidade de ramificações, e uma diminuição das mesmas com o aumento da dose.

Figura 5: Massa do caule da espécie Syzygium jambolanum 44 dias após ser aplicado o Lodo de Estação de Tratamento de Água 

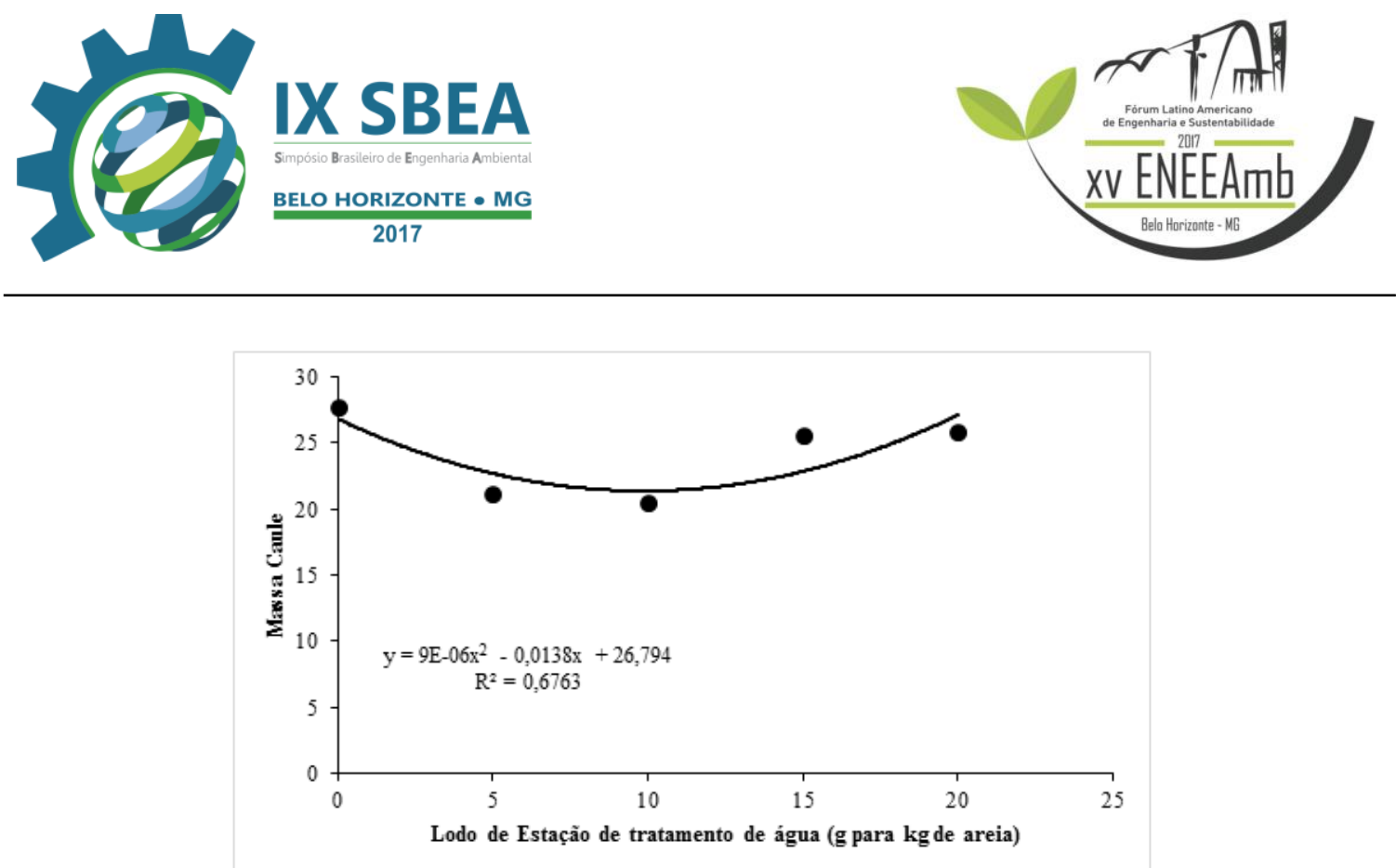

Segundo figura 5, até o tratamento 3 houve uma queda na massa do caule das plantas de Jambolão, ao ser aumentado essa quantidade de Lodo de ETA, houve aumento de massa do caule.

Figura 6: Massa das folhas da espécie Syzygium jambolanum 44 dias após ser aplicado o Lodo de Estação de Tratamento de Água

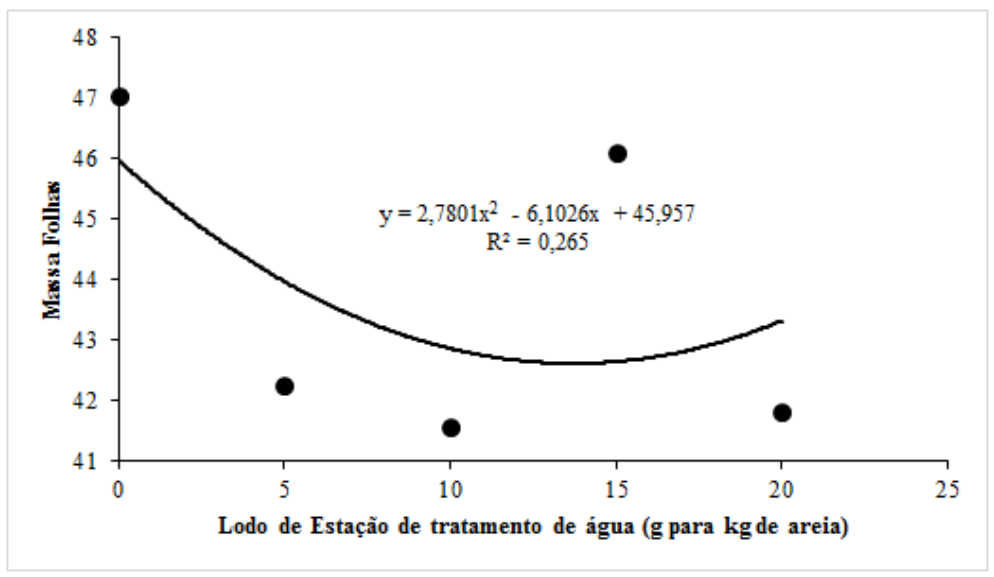

O tratamento sem aplicação do Lodo de ETA mostra uma maior massa foliar, sendo que de 13 a 15 gramas de lodo há um maior decaimento da massa das folhas.

Figura 7: Massa das folhas da espécie Syzygium jambolanum 44 dias após ser aplicado 

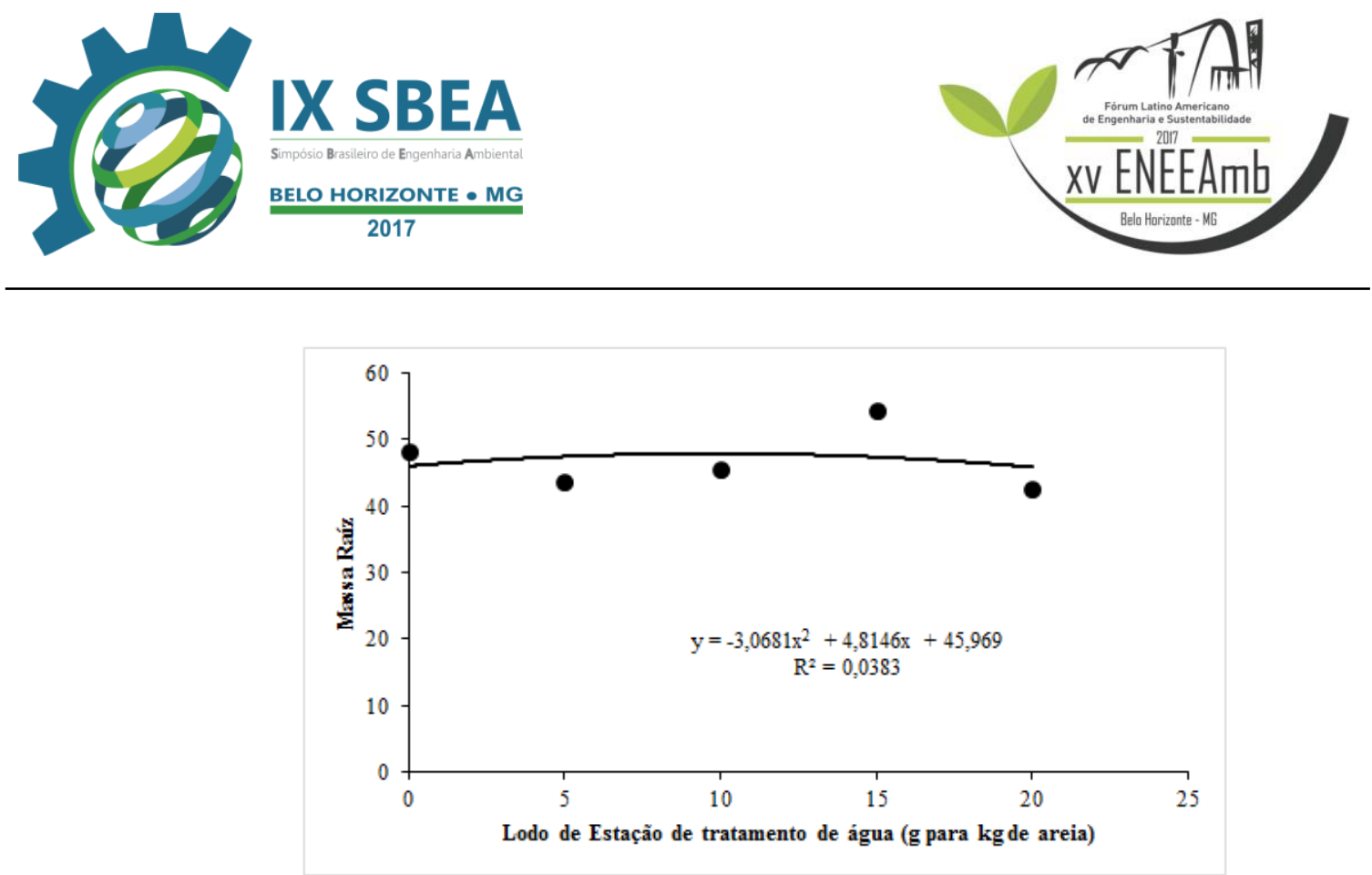

Por fim, a figura 7, o tratamento 3 mostra uma maior massa de raiz.

\section{CONCLUSÕES/RECOMENDAÇÕES}

De acordo com os dados observados, conclui-se que, a dose ideal para o cultivo de Jambolão é de 8 gramas de Lodo de Estação de Tratamento de Água por quilo de areia para um melhor desenvolvimento da espécie.

\section{REFERÊNCIAS BIBLIOGRÁFICAS}

ABNT (ASSOCIAÇÃO BRASILEIRA DE NORMAS TÉCNICAS). NBR 10004: Resíduos Sólidos- Classificação. 2 eds. Rio de Janeiro: 2004. 71 p.

ACHON, C. L. et al. Leito de drenagem: sistema natural para redução de volume de lodo de estação de tratamento de água. Engenharia Sanitária e Ambiental, v. 13, n. 1, p. 54-62, 2008.

FERNANDEZ, L. A.; FURTINI NETO, A. E.; FONSECA, F. C.; RIBEIRO DO VALE, F. Crescimento inicial, níveis críticos de fósforo e frações fosfatadas em espécies florestais. Pesquisa Agropecuária Brasileira, Brasília, v. 35, n. 6, p. 1191 1198, jun 2000. 
GANDARA, G.; BERTON, R. Aproveitamento De Lodo De Estações De Tratamento De Água No Cultivo De Milho. Disponível em: <http://www.iac.sp.gov.br/areadoinstituto/pibic/anais/2010/artigos/RE10114.pdf> Acesso em: 24 out. 2016.

PAIVA, M. W.; PARREIRA, R. L. T. Resíduos das estações de tratamento de água (ETA). Linguagem Acadêmica, Batatais, v. 2, n. 2, p. 83-96, jul./dez. 2012.

VIZZOTTO, M.; FETTER, R. Jambolão: o poderoso antioxidante. Boletim EmbrapaClima Temperado, 2009. Disponível em: < http://ainfo.cnptia.embrapa.br/digital/bitstream/CPACT-2010/12299/1/jambolaoMarcia.pdf>. Acesso em: 26 out. 2016.

ZANCAN, P. V.; TONIOLLO, M.; MIOTTO, N. Reaproveitamento de Resíduos de Etas, Uma Alternativa Para o Desenvolvimento Sustentável. VI Congresso Brasileiro de Gestão ambiental Porto Alegre/ RS. 2015. 